\title{
Impact of an internal medicine nocturnist service on care of patients with cancer at a large Canadian teaching hospital: a quality-improvement study
}

\author{
Richard Dunbar-Yaffe MDCM MSc, Robert C. Wu MD MSc, Amit Oza MBBS, Victoria Lee-Kim BMSc, \\ Peter Cram MD MBA
}

Abstract

Background: Nocturnists (overnight hospitalists) are commonly implemented in US teaching hospitals to adhere to per-resident patient caps and improve care but are rare in Canada, where patient caps and duty hours are comparatively flexible. Our objective was to assess the impact of a newly implemented nocturnist program on perceived quality of care, code status documentation and patient outcomes.

\begin{abstract}
Methods: Nocturnists were phased in between June 2018 and December 2019 at Toronto General Hospital, a large academic teaching hospital in Toronto, Ontario. We performed a quality-improvement study comparing rates of code status entry into the electronic health record at admission, in-hospital mortality, the 30-day readmission rate and hospital length of stay for patients with cancer admitted by nocturnists and by residents. Surveys were administered in June 2019 to general internal medicine faculty and residents to assess their perceptions of the impact of the nocturnist program.
\end{abstract}

Results: From July 2018 to June 2019, 30 nocturnists were on duty for 241/364 nights (66.5\%), reducing the mean maximum overnight per-resident patient census from 40 (standard deviation [SD] 4) to 25 (SD 5) $(p<0.001)$. The rate of admission code status entry was $35.3 \%$ among patients admitted by residents $(n=133)$ and $54.9 \%$ among those admitted by nocturnists $(n=339)$ $(p<0.001)$. The mortality rate was $10.5 \%$ among patients admitted by residents and $5.6 \%$ among those admitted by nocturnists $(p=0.06)$, the 30 -day readmission rate was $8.3 \%$ and $5.9 \%$, respectively $(p=0.4)$, and the mean acute length of stay was $7.2(\mathrm{SD}$ 7.0) days and 6.4 (SD 7.8) days, respectively $(p=0.3$ ). Surveys were completed by $15 / 24$ faculty (response rate $62 \%$ ), who perceived improvements in patient safety, efficiency and trainee education; however, only 30/102 residents (response rate 29.4\%) completed the survey.

Interpretation: Although implementation of a nocturnist program did not affect patient outcomes, it reduced residents' overnight patient census, and improved faculty perceptions of quality of care and education, as well as documentation of code status. Our results support nocturnist implementation in Canadian teaching hospitals.

N octurnists (overnight hospitalists) have been widely implemented in teaching hospitals in the United States in an effort to meet Accreditation Council for Graduate Medical Education workload standards, ${ }^{1}$ improve overnight supervision and enhance the quality of patient care..$^{2-8}$ Recent data indicate that about $50 \%$ of US teaching hospitals have nocturnists. ${ }^{9}$ Several single-centre surveys from the US suggest that nocturnist programs improve perceived quality of care, increase resident satisfaction with overnight supervision and may enhance efficiency., ${ }^{3,7}$ However, studies have not shown reductions in hospital length of stay or rates of mortality or hospital readmission. ${ }^{2}$

Canadian teaching hospitals have been slow to implement nocturnists. ${ }^{10}$ Nocturnal coverage is typically provided by firstyear residents from multiple disciplines, with staff available by telephone. Nocturnists are rare, and typically all admissions are performed by residents, without caps on volumes of existing patients or new admissions. Moreover, many Canadian teaching hospitals rely on teams of residents to cover all admitted medical patients, with no caps on the number of patients per resident. In contrast, in US hospitals, first-year internal medicine residents can manage a maximum of 10 patients. ${ }^{1}$

Limits on Canadian resident work hours are determined at the provincial level rather than nationally, as in the US. Only Quebec has stipulated a maximum shift length $(16 \mathrm{~h})$, with most provinces still allowing 24-hour shifts. In Europe, resident work hours are restricted to 48-hour work weeks, and 13-hour shift limits are common. ${ }^{11}$

Competing interests: None declared.

This article has been peer reviewed.

Correspondence to: Richard Dunbar-Yaffe, richard.dunbar-yaffe@uhn.ca CMAJ Open 2021. DOI:10.9778/cmajo.20200167 
Within our own institution, patient volume for internal medicine increased by $68 \%$ between 2010 and 2019; this overall growth was driven by a $188 \%$ increase in admission volume from our affiliated cancer hospital. In July 2018, we implemented a nocturnist program to address increasing patient volumes. ${ }^{12}$ To assess the impact of the program, we used patient-level data to determine its effects on documentation of resuscitation status, mortality, length of stay and readmission. We also surveyed staff and resident physicians to determine their perceptions of the program's impact.

\section{Methods}

\section{Design and setting}

We performed a quality-improvement study to assess the impact of implementation of the nocturnist program at Toronto General Hospital, a 471-bed urban quaternary teaching hospital in Toronto, Ontario.

\section{Nocturnist service implementation}

The Toronto General Hospital has a mean general internal medicine census of 120 patients, mean acute hospital length of stay of 6.1 days and an average of 16 new admissions per day, coming primarily from the emergency department. Patients admitted to general internal medicine are managed by 4 resident teams (called clinical teaching units [CTUs]) and 2 resident-independent units (RIUs). Clinical teaching units consist of an attending physician, 1 second-year or third-year resident, and 3 first-year residents, plus medical students. The average census for our CTUs is 20-25 patients, but it periodically reaches $30-35$. Our 2 RIUs are staffed by attending physicians supported by international trainees (fellows), nurse practitioners and physician assistants, and have a cap of 20 patients. One RIU is an oncology team, which manages patients with cancer receiving care at our affiliate, Princess Margaret Cancer Hospital.

Before implementation of the nocturnist service, nocturnal coverage began at 1700 and was provided by 1 first-year resident from each CTU (i.e., 4 on call each night), with supervision by a second-year resident and an off-site attending. Each on-call first-year resident was responsible for covering his or her team's 20-25 existing inpatients and admitting new patients to the team overnight. In addition, 2 of the on-call residents were each required to cross-cover an RIU; this coverage included admitting new patients to the RIU, answering pages, and assessing and managing emergent medical issues for existing RIU inpatients. In aggregate, the 2 cross-covering first-year residents covered 35-45 inpatients and admitted 4-6 new patients per night.

Our nocturnist program was introduced in a graduated manner, with nocturnal coverage increasing over time. Nocturnist shifts were offered to current faculty and independently licensed physicians from the community. Ontario physicians are compensated primarily on a fee-for-service basis by the Ministry of Health, with supplemental payments for off-hours work. ${ }^{13}$ However, competition in the local market necessitated hospital supplementation (about $\$ 1500$ per night) to entice physicians to cover nights. Nocturnist shifts are from 1700 to 0800. Nocturnists are responsible for admissions to the oncology RIU plus overnight coverage of the existing census of both RIUs; they are not expected to supervise trainees.

\section{Participants and outcomes}

\section{Survey}

Faculty survey participants were general internal medicine physicians (full-time and part-time) who attended on our CTUs in June 2019. This did not include most of the temporary and casual staff who performed the majority of nocturnist shifts during the study period. We also emailed surveys to all residents at the end of their 4-week CTU rotation at our hospital between June and December 2019. Residents at Toronto General Hospital all regularly work in other University of Toronto teaching hospitals, all of which lack nocturnists, which enabled them to assess the addition of a nocturnist program.

\section{Patients}

We identified all patients with cancer admitted to the oncology RIU by residents on nights when no nocturnist was on duty and by nocturnists on nights when nocturnists were on duty between July 1, 2018, and June 30, 2019. As nocturnist availability was quasi-random during our ramp-up phase, we expected that patients admitted by residents and nocturnists would generally be similar. There were no exclusion criteria for patients.

For these 2 groups of patients, we compared entry of a code status order in the electronic health record by 0800 on the day of admission, in-hospital death, hospital length of stay and 30-day readmission rate. We selected outcomes commensurate with prior literature evaluating nocturnist programs for which data were available through our hospital's data warehouse. ${ }^{2}$ Preventable readmissions are a target of concern for hospitals and payers; although there are other contributing factors, it is conceivable that some aspect of the initial admission may influence this outcome.

\section{Data sources}

\section{Survey}

In June 2019, 1 year after implementation of the nocturnist program, we emailed surveys to all physicians who had attended on the general internal medicine CTUs. The survey was developed by 2 of the authors (R.D.-Y. and V.L.-K.). Questions related to perceptions of quality of care, perceived errors and expeditious patient evaluation were adapted from a similar single-centre study of implementation of a nocturnist program, ${ }^{7}$ and those related to burnout and suspected reasons for postintervention improvement were developed by the authors (Appendices 1 and 2, available at www.cmajopen.ca/ content/9/2/E667/suppl/DC1). The survey contained additional space for optional free-text responses. The survey was pilot-tested with 2 of the authors (R.C.W. and P.C.), the chief medical resident and 2 other faculty members to ensure 
clarity of phrasing and response options; this resulted in only minor modifications. Minimal demographic data were collected to protect confidentiality given the small numbers of participants.

\section{Patients}

We obtained patient-level data (e.g., age, sex, admission date, comorbidity) abstracted from our hospital's electronic health record data warehouse, which complies with Canadian coding standards $s^{14}$ and can be provided to hospital staff by request. Comorbidity was captured in this database by means of the Charlson Comorbidity Index (score range 0-37; higher scores represent a higher burden of illness). ${ }^{15}$ Code status entry was obtained by 1 of the authors (R.D.-Y.) by reviewing the patients' charts and noting the timestamp in the electronic health record of code status entry; this is our hospital's contemporary and sole standard for documenting and referring to code status.

\section{Patient census}

We used electronic health record data to determine the daily patient census covered by each resident. We used call schedules to combine censuses for residents scheduled to cover their own CTU plus an RIU (i.e., cross-covering). We used a spreadsheet with nocturnist call assignments to determine the number of shifts covered by each physician, and their status as faculty or temporary physicians.

\section{Statistical analysis}

We compared demographic characteristics, temporal factors (weekend v. weekday admissions) and comorbidity for patients admitted by nocturnists and residents using bivariate measures. We compared resident census coverage on nights with and without a nocturnist using a $t$ test. We examined survey responses using standard descriptive statistics (i.e., mean, median, percentages) in Microsoft Excel. For dichotomous (yes/no) questions, we examined the proportion of respondents who answered "Yes." For Likert-type questions (scored from 1 [strongly disagree] to 5 [strongly agree] except for the question regarding satisfaction, where $1=$ very unsatisfied and $5=$ very satisfied), we calculated the mean score for each item. We reviewed free-text survey responses for any concerns that were not included in the survey rather than coding them for formal qualitative review.

We compared unadjusted outcomes for patients admitted on nights with and without nocturnist coverage, and adjusted analyses using logistic regression to control for differences in age, sex and Charlson Comorbidity Index score, as well as weekend admission. We compared the Charlson Comorbidity Index score and acute hospital length of stay for patients admitted by nocturnists and those admitted by residents using $t$ tests in SPSS (SPSS Software, IBM Corporation).

\section{Ethics approval}

Our survey was considered quality improvement and deemed exempt from ethics review by the University Health Network Research Ethics Board (waiver 19-0338).

\section{Results}

\section{Patient outcomes}

Nocturnist coverage was present for $241(66.2 \%)$ of 364 nights between July 1, 2018, and June 30, 2019, with 46 nights $(19.1 \%)$ covered by full-time faculty and 195 nights $(80.9 \%)$ by temporary staff. Patients admitted by nocturnists $(n=339)$ and those admitted by residents $(n=133)$ were similar with respect to age, sex and Charlson Comorbidity Index score (Table 1). Ninety-four (27.7\%) of the nocturnist admissions were performed on weekends, compared to $30(22.6 \%)$ of the resident admissions $(p=0.2)$.

In-hospital mortality was not statistically significantly different for patients admitted by residents (10.5\%) as compared to nocturnists (5.6\%) (adjusted odds ratio [OR] 1.91, 95\% confidence interval [CI $0.92-4.00)$. Of the 133 patients admitted by residents, $11(8.3 \%)$ were readmitted to our hospital within 30 days of discharge, compared to $20(5.9 \%)$ of the 339 admitted by nocturnists (adjusted OR 1.35, 95\% CI 0.62-2.94). The mean acute length of stay for patients admitted by residents was 7.2 (standard deviation [SD] 7.0) days, compared to 6.4 (SD 7.8) days for those admitted by nocturnists $(p=0.3)$. Entry of code status orders was more common for admissions performed by nocturnists than by residents (186 [54.9\%] v. 47 [35.3\%], $p<0.001$ ).

\section{Patient census}

Among the 30 physicians (5 faculty, 25 temporary) who worked on the nocturnist service, the median number of nocturnist shifts performed per physician during the study period was 5.5 (interquartile range [IQR] 2.0-9.8). Among the 123 nights without a nocturnist, the 2 residents required to cross-cover the RIUs had a mean overnight census of 40.0 (SD 3.9) patients, compared to 25.2 (SD 4.7) patients for the 2 residents not required to cross-cover $(p<0.001)$.

\begin{tabular}{|c|c|c|c|}
\hline \multirow[b]{2}{*}{ Characteristic } & \multicolumn{2}{|c|}{ No. $(\%)$ of patients* } & \multirow[b]{2}{*}{$p$ value } \\
\hline & $\begin{array}{l}\text { Admitted by } \\
\text { residents } \\
n=133\end{array}$ & $\begin{array}{c}\text { Admitted by } \\
\text { nocturnists } \\
n=339\end{array}$ & \\
\hline Age, mean $\pm S D, y r$ & $61.7 \pm 14.5$ & $60.4 \pm 14.7$ & 0.4 \\
\hline Female sex & $58(43.6)$ & $159(46.9)$ & 0.5 \\
\hline Weekend admission & $30(22.6)$ & $94(27.7)$ & 0.2 \\
\hline $\begin{array}{l}\text { Charlson Comorbidity } \\
\text { Index score, mean } \pm \text { SD }\end{array}$ & $4.6 \pm 3.0$ & $4.4 \pm 3.1$ & 0.6 \\
\hline In-hospital death & $14(10.5)$ & $19(5.6)$ & 0.06 \\
\hline Readmitted & $11(8.3)$ & $20(5.9)$ & 0.4 \\
\hline $\begin{array}{l}\text { Acute length of stay, } \\
\text { mean } \pm S D, d\end{array}$ & $7.2 \pm 7.0$ & $6.4 \pm 7.8$ & 0.3 \\
\hline Documented code status & $47(35.3)$ & $186(54.9)$ & $<0.001$ \\
\hline
\end{tabular}




\begin{tabular}{|c|c|}
\hline Question & $\begin{array}{l}\text { No. }(\%) \text { of } \\
\text { respondents* } \\
n=15\end{array}$ \\
\hline $\begin{array}{l}\text { Any experience with Toronto General Hospital } \\
\text { general internal medicine-oncology Overnight } \\
\text { Hospitalist program in clinical experience at } \\
\text { Toronto General Hospital }\end{array}$ & $15(100)$ \\
\hline $\begin{array}{l}\text { Satisfaction with overall quality of care delivered at } \\
\text { Toronto General Hospital, mean Likert score } \pm \text { SD }\end{array}$ & $3.6 \pm 1.7$ \\
\hline \multicolumn{2}{|l|}{$\begin{array}{l}\text { Since development of the Overnight Hospitalist } \\
\text { program, the quality of care delivered at Toronto } \\
\text { General Hospital general internal medicine has: }\end{array}$} \\
\hline Improved & $11(73)$ \\
\hline Stayed the same & $2(13)$ \\
\hline Decreased & $2(13)$ \\
\hline $\begin{array}{l}\text { The Overnight Hospitalist program has decreased } \\
\text { medical errors, mean Likert score } \neq \pm S D\end{array}$ & $3.6 \pm 1.2$ \\
\hline $\begin{array}{l}\text { The Overnight Hospitalist program leads to faster } \\
\text { overnight evaluation of patients who are already } \\
\text { admitted on the wards, mean Likert score } \pm \text { SD }\end{array}$ & $4.6 \pm 0.9$ \\
\hline $\begin{array}{l}\text { The Overnight Hospitalist program leads to faster } \\
\text { evaluation of new patients in the emergency } \\
\text { department, mean Likert score } \ddagger \pm S D\end{array}$ & $4.5 \pm 0.9$ \\
\hline $\begin{array}{l}\text { The educational experience on the internal } \\
\text { medicine CTU has improved as a result of the } \\
\text { Overnight Hospitalist program, mean Likert } \\
\text { score } \pm \text { SD }\end{array}$ & $4.1 \pm 1.3$ \\
\hline \multicolumn{2}{|l|}{$\begin{array}{l}\text { Effect of the Overnight Hospitalist program on } \\
\text { your medical billings }\end{array}$} \\
\hline No change & $7(47)$ \\
\hline Decrease & $2(13)$ \\
\hline Not sure & $6(40)$ \\
\hline $\begin{array}{l}\text { The Overnight Hospitalist program makes the } \\
\text { hospital more attractive to residents, mean Likert } \\
\text { score } \pm \text { SD }\end{array}$ & $4.0 \pm 1.7$ \\
\hline $\begin{array}{l}\text { The Overnight Hospitalist program has reduced } \\
\text { trainee burnout, mean Likert score } \neq \pm S D\end{array}$ & $4.1 \pm 1.0$ \\
\hline $\begin{array}{l}\text { The Overnight Hospitalist program has reduced } \\
\text { faculty/attending physician burnout, mean Likert } \\
\text { score } \pm \text { SD }\end{array}$ & $3.5 \pm 1.0$ \\
\hline $\begin{array}{l}\text { The Overnight Hospitalist program improves my } \\
\text { satisfaction while attending at Toronto General } \\
\text { Hospital, mean Likert score } \pm \text { SD }\end{array}$ & $4.1 \pm 1.1$ \\
\hline
\end{tabular}

\section{Survey responses}

We received responses from 15 (63\%) of 24 faculty, of whom $11(73 \%)$ were full-time faculty members with a median of 9.0 (IQR 3.5-15.0) years in practice. Most respondents (11 $[73 \%])$ thought that the nocturnist program had improved the quality of care, $9(60 \%)$ perceived a reduction in medical errors, and $11(73 \%)$ reported an improvement in resident educational experience (Table 2). The perceived benefits of the nocturnist program most commonly selected by the respondents were a reduced need for residents to hand over to
Table 2 (part 2 of 2): Faculty survey responses

\begin{tabular}{|c|c|}
\hline Question & $\begin{array}{l}\text { No. }(\%) \text { of } \\
\text { respondents* } \\
n=15\end{array}$ \\
\hline \multicolumn{2}{|l|}{ Benefits of the Overnight Hospitalist program§ } \\
\hline $\begin{array}{l}\text { Trainees have no need to obtain handover } \\
\text { from or cross-cover teams overnight }\end{array}$ & $12(80)$ \\
\hline $\begin{array}{l}\text { Trainees do not need to hand over in the } \\
\text { morning to more than } 1 \text { team }\end{array}$ & $11(73)$ \\
\hline $\begin{array}{l}\text { Trainees do not need to admit to more than } \\
1 \text { team overnight }\end{array}$ & $9(60)$ \\
\hline $\begin{array}{l}\text { Trainees have fewer patients to evaluate and } \\
\text { admit from the emergency department } \\
\text { overnight }\end{array}$ & $12(80)$ \\
\hline $\begin{array}{l}\text { Trainees do not need to manage transfers } \\
\text { from other hospitals to the ward overnight }\end{array}$ & $6(40)$ \\
\hline $\begin{array}{l}\text { Trainees have fewer distractions from their } \\
\text { admitting and call duties when working } \\
\text { overnight }\end{array}$ & $11(73)$ \\
\hline $\begin{array}{l}\text { There is a dedicated physician in house to } \\
\text { cover general internal medicine-oncology } \\
\text { patients (Team 10) }\end{array}$ & $13(87)$ \\
\hline $\begin{array}{l}\text { There is a dedicated physician in house to } \\
\text { admit general internal medicine-oncology } \\
\text { patients (Team 10) }\end{array}$ & $14(93)$ \\
\hline $\begin{array}{l}\text { The physician covering general internal } \\
\text { medicine-oncology patients (Team 10) and } \\
\text { admitting new patients to Team } 10 \text { is more } \\
\text { experienced }\end{array}$ & $12(80)$ \\
\hline $\begin{array}{l}\text { There is a greater likelihood that the trainee } \\
\text { will be able to rest/sleep overnight }\end{array}$ & $4(27)$ \\
\hline $\begin{array}{l}\text { There is a greater likelihood that I will be able } \\
\text { to rest/sleep overnight }\end{array}$ & $6(40)$ \\
\hline $\begin{array}{l}\text { There is a reduced need for trainees to } \\
\text { communicate with the attending physician } \\
\text { overnight }\end{array}$ & $6(40)$ \\
\hline $\begin{array}{l}\text { The nurses have improved access to } \\
\text { physicians overnight regarding urgent patient } \\
\text { issues }\end{array}$ & $8(53)$ \\
\hline None of the above & $1(7)$ \\
\hline $\begin{array}{l}\text { Note: CTU = clinical teaching unit, SD = standard deviation } \\
\text { "Except where noted otherwise. } \\
\text { †Rated on a 5-point scale where } 1=\text { very unsatisfied and } 5 \\
\text { †Rated on a 5-point scale where } 1=\text { strongly disagree and } \\
\text { §Respondents could select all that applied. }\end{array}$ & $\begin{array}{l}\text { ry satisfied. } \\
\text { strongly agree. }\end{array}$ \\
\hline
\end{tabular}

multiple different teams in the morning; a reduced number of admissions per resident; and less cross-coverage of RIU teams, with resultant improvements in care for patients on the RIUs. Most respondents perceived a reduction in burnout among faculty (mean Likert score 3.5 [SD 1.0]) and residents (mean Likert score 4.1 [SD 1.0]).

We received completed surveys from 30 (29.4\%) of 102 residents, 25 of whom were in the general internal medicine program. Given the low response rate, these results were considered exploratory. Key findings included a perception of 
expedited patient evaluation, reduced medical errors, improved educational experience and reduced burnout. Additional detail is available in Appendix 2, Supplemental Table S1.

Few free-text survey responses were received.

\section{Interpretation}

Our nocturnist program reduced the number of patients that residents were managing overnight. Faculty perceived that patient safety (in terms of decreased medical errors) and trainee educational experience were improved. The program was associated with increased documentation of code status but, as expected, had no statistically significant effect on mortality, the readmission rate or length of stay. Our survey respondents reported a reduction in perceived burnout, which may be linked to workload; ${ }^{16,17}$ however, no validated tool was used to assess this objectively. Together, these results suggest that implementation of a nocturnist program can address pressing concerns facing Canadian teaching hospitals. ${ }^{18}$

Our finding that our nocturnist program reduced the patient census for trainees, although expected, is important. In addition to trainees' experiencing sleep deprivation and resultant effects on cognitive performance, ${ }^{19}$ the complexity of patients' conditions is increasing, ${ }^{20}$ and both societal and physician norms and expectations are changing with respect to workload and work hours. ${ }^{11}$ In the United Kingdom, nocturnal reliance on physicians-in-training motivated the Hospital at Night program, ${ }^{21}$ in which specialty-specific nocturnal physician care was replaced by multidisciplinary teams, sometimes led by nurse practitioners. Overnight staffing changes were only part of the model. The Hospital at Night program has resulted in improvements in hospital-wide care, with net cost reduction..$^{21}$

Our study adds to the existing literature regarding the impact of nocturnists on quality of care. A survey by Trowbridge and colleagues ${ }^{7}$ showed that the nocturnist program at an academic medical centre in the US was perceived by both residents and faculty to improve the quality of care. A 2012 survey of US academic hospitalist program directors by Farnan and colleagues ${ }^{8}$ showed that $61 \%$ of programs had nocturnists and $24 \%$ functioned independently from the teaching teams. Those authors found perceived improvements in patient safety but potential reductions in resident autonomy; a more recent study showed similar findings. ${ }^{9}$ Our survey respondents also felt that the introduction of nocturnists allowed for more rapid evaluation of both new and existing patients.

Our finding that faculty perceived favourable impacts on education and training is somewhat consistent with prior literature. ${ }^{7}$ For example, a survey of residents at a tertiary care academic medical centre in the US showed that nocturnists enhanced trainee perceptions of overnight supervision. ${ }^{4}$ Conversely, Devendra and colleagues ${ }^{22}$ reported a potential educational cost to nocturnist supervision at an urban US medical centre affiliated with an internal medicine residency program.
Our findings that mortality, hospital length of stay and readmissions were not significantly decreased with the nocturnist program are similar to results of Gonzalo and colleagues. ${ }^{2}$ However, the difference in the mortality rate between patients admitted by residents and those admitted by nocturnists $(10.5 \%$ v. $5.6 \%)$ was quite large clinically. With similar baseline characteristics and postadmission care, it is unclear what may have been responsible for this difference. It is plausible that, given the higher census and longer shifts for Canadian residents than for their US peers, nocturnist programs may confer larger benefits in Canadian hospitals. Further study is warranted to see whether these differences are replicated in other Canadian centres.

Patients admitted by nocturnists were significantly more likely than those admitted by residents to have their code status entered into the electronic health record. Documentation of code status is recognized as an important process measure in hospital medicine and provides tangible evidence of improvements in quality. ${ }^{23,24}$ Although not altogether surprising, this finding reinforces the potential benefits of reducing resident workload and shifting some proportion of new admissions onto experienced hospitalists.

It would be important to formally explore potential drawbacks of nocturnist interventions, including additional handovers, less daytime accountability for overnight issues and lower billings, highlighting the importance of early faculty engagement in similar interventions. Graded responsibility is a hallmark of resident education, and further study is required to determine whether residents perceive the nocturnist as an impediment to the development of clinical independence.

It is also important to recognize the financial support required to implement our program and its potential impact on the "daytime" physician's income. Having an in-house attending physician could reduce the total amount billable to the attending physicians on our RIUs. Incentivizing night work also required a substantial stipend, beyond the fee-forservice income that was generated. Although residents are important care providers, their salaries come from provincial monies rather than hospital budgets. Therefore, employing nocturnists to supplement resident shortages represents a net new cost to Canadian hospitals.

\section{Limitations}

The survey response rate from residents was low, and, although the results were mainly congruent with the perceptions of faculty respondents, we consider them exploratory. Our surveys were anonymous, which did not allow identification of nonresponders; together with hospital policies on email volume, this limited our ability to remind nonresponders. Furthermore, multiple residents may have rotated several times through the CTU during the study period and may have been counted in our denominator more than once. The low survey response rate from residents may have introduced nonresponder bias, and social desirability bias may have influenced how respondents answered our survey questions. However, the survey responses were consistent with prior survey-based findings of nocturnist programs 
from the US. ${ }^{2,7,9}$ Given the methodologic limitations inherent in self-reported surveys, confirmation of the perceived benefits reported by respondents should be confirmed with objective outcome measures.

Our study was conducted in a single Canadian teaching hospital; as such, our findings must be generalized with care. We did not assess the impact of nocturnists on patient satisfaction or other patient-reported outcomes that might be improved by nocturnists. ${ }^{25}$

\section{Conclusion}

Implementation of the nocturnist program reduced resident workload, and improved faculty perceptions of quality of care, patient safety and educational experiences, as well as documentation of code status. Although there was no statistically significant effect on patient outcomes, our findings, in combination with existing literature, support implementation of nocturnists across Canadian teaching hospitals.

\section{References}

1. ACGME program requirements for graduate medical education in internal medicine. Chicago: Accreditation Council for Graduate Medical Education; revised 2020. Available: www.acgme.org/Portals/0/PFAssets/ProgramRequirements/140_ InternalMedicine_2020.pdf (accessed 2020 June 15).

2. Gonzalo JD, Kuperman EF, Chuang CH, et al. Impact of an overnight internal medicine academic hospitalist program on patient outcomes. 7 Gen Intern Med 2015;30:1795-802.

3. Tanios MA, Teres D, Park H, et al. The impact of implementing an intensivist model with nighttime in-hospital nocturnist and effect on ICU outcomes. 7 Intensive Care Med 2020;35:461-7.

4. Haber LA, Lau CY, Sharpe BA, et al. Effects of increased overnight supervision on resident education, decision-making, and autonomy. 7 Hosp Med 2012; 7:606-10.

5. Greene JG. Neurohospitalists enhance resident perception of the educational and clinical value of a night float rotation. Neurobospitalist 2013;3:179-84.

6. Sani SN, Wistar E, Le L, et al. Shining a light on overnight education: hospitalist and resident impressions of the current state, barriers, and methods for improvement. Cureus 2018;10:e2939.

7. Trowbridge RL, Almeder L, Jacquet M, et al. The effect of overnight in-house attending coverage on perceptions of care and education on a general medical service. 7 Grad Med Educ 2010;2:53-6.

8. Farnan JM, Burger A, Boonyasai RT, et al.; SGIM Housestaff Oversight Subcommittee. Survey of overnight academic hospitalist supervision of trainees. 7 Hosp Med 2012;7:521-3.

9. Catalanotti JS, O'Connor AB, Kisielewski M, et al. Association between nocturnist supervision and perceived overnight supervision adequacy among internal medicine residents in the US. FAMA 2020;323:1407-9.

10. Walkinshaw E. Middle-of-the-night medicine is rarely patient-centred. CMAJ 2011;183:1467-8.

11. Temple J. Resident duty hours around the globe: Where are we now? BMC Med Educ 2014;14(Suppl 1):S8.

12. Verma AA, Guo Y, Kwan JL, et al. Patient characteristics, resource use and outcomes associated with general internal medicine hospital care: the General Medicine Inpatient Initiative (GEMINI) retrospective cohort study. CMAf Open 2017;5:E842-9.

13. Henry DA, Schultz SE, Bhatia S, et al. Payments to Ontario physicians from Ministry of Health and Long-Term Care sources, 1992/93 to 2009/10: ICES investigative report. Toronto: ICES; 2012.

14. Canadian coding standards for version 2015 ICD-10-CA and CCI. Ottawa: Canadian Institutes for Health Information; 2015.

15. Charlson ME, Pompei P, Ales KL, et al. A new method of classifying prognostic comorbidity in longitudinal studies: development and validation. $\mathcal{F}$ Chronic Dis 1987;40:373-83.
16. Portoghese I, Galletta M, Coppola RC, et al. Burnout and workload among health care workers: the moderating role of job control. Saf Health Work 2014; 5:152-7.

17. Dyrbye LN, Burke SE, Hardeman RR, et al. Association of clinical specialty with symptoms of burnout and career choice regret among US resident physicians [retraction of Dyrbye LN, Burke SE, Hardeman RR. In: FAMA 2018; 320:1114-30]. FAMA 2018;320:1114-30.

18. Cram P, Chopra V, Soong C, et al. Reimagining inpatient care in Canadian teaching hospitals: Bold initiatives or tinkering at the margins? 7 Hosp Med 2019;14:251-3.

19. Levine AC, Adusumilli J, Landrigan CP. Effects of reducing or eliminating resident work shifts over 16 hours: a systematic review. Sleep 2010;33:1043-53.

20. Clark AV, LoPresti CM, Smith TI. Trends in inpatient admission comorbidity and electronic health data: implications for resident workload intensity. 7 Hosp Med 2018;13:570-2.

21. Hamilton-Fairley D, Coakley J, Moss F. Hospital at night: an organizational design that provides safer care at night. BMC Med Educ 2014;14(Suppl 1):S17.

22. Devendra GP, Ortiz GM, Haber LA. By the light of day: quality, safety, and education during the overnight admission handoff. Cureus 2019;11:e4529.

23. Brizzi K, Zupanc SN, Udelsman BV, et al. Natural language processing to assess palliative care and end-of-life process measures in patients with breast cancer with leptomeningeal disease. Am 7 Hosp Palliat Care 2020;37:371-6.

24. Palliative care: care for adults with a progressive, life-limiting illness. Toronto: Health Quality Ontario; 2017.

25. Mathews BK. Capsule Commentary on Gonzalo, et al., Impact of an overnight internal medicine academic hospitalist program on patient outcomes. 7 Gen Intern Med 2015;30:1850.

Affiliations: Division of General Internal Medicine and Geriatrics (Dunbar-Yaffe, Wu, Cram), Sinai Health System and University Health Network; Division of General Internal Medicine (Dunbar-Yaffe, Wu, Cram), Department of Medicine, University of Toronto; Division of Medical Oncology and Hematology (Oza), University Health Network, Toronto, Ont.; School of Medicine (Lee-Kim), Queen's University, Kingston, Ont.

Contributors: Richard Dunbar-Yaffe, Victoria Lee-Kim, Robert Wu and Peter Cram conceived of the study. Richard Dunbar-Yaffe and Victoria Lee-Kim acquired and interpreted the data. All of the authors contributed to the study design, data analysis and drafting of the manuscript, revised the manuscript critically for important intellectual content, approved the final version to be published and agreed to be accountable for all aspects of the work.

Funding: Peter Cram is supported by grant R01AG058878 from the US National Institute of Aging and by a Salary Award from the Temerty Faculty of Medicine, University of Toronto. Robert $\mathrm{Wu}$ is supported by an award from the Mak Pak Chiu and Mak-Soo Lai Hing Chair in General Internal Medicine, University of Toronto.

Content licence: This is an Open Access article distributed in accordance with the terms of the Creative Commons Attribution (CC BY-NCND 4.0) licence, which permits use, distribution and reproduction in any medium, provided that the original publication is properly cited, the use is noncommercial (i.e., research or educational use), and no modifications or adaptations are made. See: https://creativecommons.org/licenses/ by-nc-nd/4.0/.

Data sharing: Anonymized data may be available on request to the corresponding author.

Acknowledgement: The authors thank Dr. Brian Hodges for helpful comments on the manuscript.

Supplemental information: For reviewer comments and the original submission of this manuscript, please see www.cmajopen.ca/content/9/2/ E667/suppl/DC1. 